\title{
Are the Healthcare Professionals Really Satisfied with What they Cared? Evidence from an Armed Forces Hospital in Taiwan
}

\author{
Wei-Wen Liu \\ Central Taiwan University of Science and Technology
}

Frank Pan

(Corresponding Author)

Tajen University, Taiwan, 20, Weixin Rd., Yampu, Pingtung, Taiwan, ROC

Tel: 886-8-7624002Ｅ-mail: profpan900@gmail.com

Wan-Hsyu Shieh

Central Taiwan University of Science and Technology

Accepted: Sep 03, 2013 Published: October 10, 2013

Doi:10.5296/jsr.v4i2.4400ＵRL: http://dx.doi.org/10.5296/jsr.v4i2.4400

\begin{abstract}
Squeezed by the new reimbursement policy of the National Health Insurance (NHI) in Taiwan, the Armed Forces Hospitals (AFH) had to serve general citizens as well as military clients. A dual role of military services and resource generator it acts in the current healthcare industry. Consequently, the job satisfaction of hospital staffs had thus been influenced. Taken the importance of the employee's job satisfaction in customer satisfaction as well as in overall profit into account, the current research wished to reveal the current levels of the hospital employee's job satisfaction, and to compare the differences of the perceived importance and the actual experience of satisfaction attributes. Main questions this research to answer were "Does the healthcare professionals satisfied with what they perceived important?" and "What are the main discrepancies exist that worth for investing? Using a structural questionnaire as an instrument, 474 valid responses from an armed forces hospital in central Taiwan were used as sample. The study reveals that there are significant differences between perceived
\end{abstract}


importance and experience in each dimension, of which the compensation system was perceived the most important and in the meantime having the biggest gap between expectation and experience. The findings suggest that the hospital managers should re-organize the compensation system by increasing the incentives of bonuses, promotions, while maintain those aspects with smaller differences such as job content and supervision to effectively motivate the hospital employees, and accordingly ameliorating medical service quality.

Keywords: Armed Forces Hospital, Job Satisfaction, Perceived Importance, Healthcare professional

\section{Introduction}

Human resources experts both in the academic and the industry had generally agreed that human resource is the most important assert a firm can possessed in building competitive advantage in the modern knowledge-based competition environment. It is particularly true in the service industries, as the theory of service profit chain had claimed and proofed, only when the satisfied employees may deliver quality service to the customers, the organization can gain profit (Oliver, 1980, 1993; Lovelock \& Wirtz, 2010; Alamro \& Rowley, 2011). Since job satisfaction had been generally accepted as one of major predictors of productivity. Although certain organizations such as government agencies or non-profit organizations, earing profit may not be part of mission, productivity of any employee that lower than an acceptable level as expected by the organization as well as the customers (or clients, service receivers) may mean a resource waste.

It is common to find that plenty of firms generously proclaim to allocate resources to foster good levels of employee's job satisfaction in many forms of statements, including corporate mission or company policy. Many of them further provide tremendous evidences, such as fringe benefit, paid vacation, corporate insurance, promotion opportunity, modern and comfortable job environment, and many others in their recruit announcements or public reports. Indeed, there are great part of management in the industries highly intend to provide sufficient facilities (both physical environment in the hard side and others in the soft) to cheer their employee, to foster good levels of job satisfaction.

Although the management of a hospital may perceive the importance of the link between employee's job satisfaction and performance, and accordingly the service quality delivered to the patients, the management may wrongly invest efforts in those aspects that not valuable to the employee, of which make the efforts void (Hammasi, Strong, \& Taylor, 1994; Lovelock \& Wirtz, 2010). One question may be more important than the job satisfaction itself, that is does the dimensions the employee satisfied are the same as those they perceived important ones? And what are the major discrepancies exist in these dimensions? It is clear that identifying the major gaps between perceived important dimensions and satisfied can guide the management's efforts in improving overall job satisfaction in an effective manner. Resources can be very limited in a highly competitive healthcare markets in Taiwan, and well-designed resource allocation to the right aspects is critical. 


\section{Literature review}

\subsection{Armed Forces Hospitals in Taiwan}

Historically, the Armed Forces Hospitals (AFH, or Military Hospital) were formed under a mission of supporting the medical needs of the entire troops of the country. This is particularly important for the country on that time during and after the World War II to maintain a high level of mobility of deployable troops for the national defense and national security, when the medical resources were precious and not easy accessible.

The roles of AFH had largely tuned to both caring the armed forces around the country and providing general healthcare services to the civilians lately. This means the military hospitals have to allocate part of its resources to compete patients in an open market to gain more financial independence. The management of an AFH typically is short in of business disciplines. These generals and colonels are experts of war and fighting tactics, yet not in the business battle field.

Despite that there is certain amount of civilian staff, the management and major personnel in the AFHS are military servants. Unique problems can be expected when managing a pool of human resource that combining military personnel and civilian. As the case in the current research, motivating the work force may greatly deviate from what were true in general research. This means any attempt drawn from rules or conclusions based on other forms of hospital or organization may be less effective, if not fail, to motivate the employee's job satisfaction.

\subsection{Job satisfaction}

Job satisfaction is generally defined or interpreted as a psychological or affective status that reflect an employee's satisfaction levels toward the work content and associated environment of the job the employee been assigned (Hoppock, 1935, Vroom, 1964). Level of job satisfaction is an outcome of comparing the expected values and actual experiences of a job, and is highly subjective and person-specific. Satisfaction will be high when the discrepancy of expectation and experienced is low, and vice versa. A model that proposed by Christen, Iyer, \& Soberman (2006) had argued that measuring a job satisfaction may include job related factors (job content in this research), role perceptions (job content), job performance (compensation, and evaluation in the current research), and firm performance. We argue that the compensation system can substantially reflect a firm's performance, at least in an objective manner. In addition, according to the environment psychology as well as the concept of servicescape (Baker, 1987; Bitner, 1992), the environmental factor can significantly shape the individuals' mental and physical behaviors (Baker, Berry, \& Parasuraman, 1988, Bitner, 1992; Turley \& Milliman, 2000). Same effects can also be found in the quality of interpersonal relationship, of which is generally included as part of environmental factors. This is particularly important in the labor-intensive that require highly cross-sectional cooperation. We thus include environmental factors and interpersonal as part of attributes to the job satisfaction in this research.

A job may be featured with a wide variety of characteristics, technical or physical 
requirements, varied physical facilities and colleagues, and varied levels of supervision or control, as well as varied compensation systems. Thus, expectation toward a job may vary one employee to another. For example, some may perceive job enrichment is important while the others may prefer a routine work. As a result, satisfaction to a job will also vary across entire work force. Although attempting to satisfy all employee of entire organization is not logical (and not economical), creating and maintaining good levels of overall job satisfaction is important.

Strong correlation has been found between job satisfaction of a person and his/her family, organization, and society. People with high levels of job satisfaction tend to be more pleased, more stable in emotion, own better economic status, and more active in participating social affairs. This means job satisfaction can not only provide productivity and better customer satisfaction to the organization, but also improve the welfare of the society.

Factors behind the levels of job satisfaction are complicated and varied from one particular job to another. Although there is no consensus regarding a complete model that explaining the job satisfaction, the academicians generally agreed that personal characteristics and the job per se played critical roles. For example, levels of satisfaction are found varied with categories or nature of a job, supervision responsibility, gender, age, education, marriage, tenure, and more recently the person-job fit.

\section{Materials and Methods}

\subsection{Measurement}

Based on the cognitive model of Oliver (1980), the instrument that derived from Barbara, Jaffe, \& Lin (1994) is used to measure the construct of job satisfaction. Data was collected by a structured questionnaire with acceptable reliability, in which performance assessment dimension is 0.961 , compensation is 0.943 , job content is 0.957 , job environment is 0.947 , supervising is 0.959 , and interpersonal relationship is 0.947 , and the overall reliability is 0.952 , shown as table 1 .

Table 1 Reliability of construct and dimensions

\begin{tabular}{lc}
\hline \multicolumn{1}{c}{ Dimension } & Cronbach's $\alpha$ \\
\hline Job Content & 0.957 \\
Work Environment & 0.947 \\
Supervision & 0.959 \\
Interpersonal Relationship & 0.947 \\
Compensation & 0.943 \\
Evaluation & 0.961 \\
\hline Overall & 0.975 \\
\hline
\end{tabular}

\subsection{Ethics of research}

This research had gained an approval from the committee of medical ethics of the targeted hospital (as attached appendix). The respondents fill a written consent that stating the research is fully restricted as an academic use and the respondents have full rights to 
withdraw from the research at any time.

\subsection{Samples}

In the period between December 26 and-31 of 2011, 576 responses were obtained from 750

\begin{tabular}{llrrr}
\hline Variables & Categories & $\mathrm{n}$ & \multicolumn{1}{c}{ Accu. \% } \\
\hline Occupation & Physician & 48 & 10.1 & 10.1 \\
& Nurse & 206 & 43.5 & 53.7 \\
Gender & Administration & 143 & 30.2 & 83.9 \\
& Technician & 76 & 16.0 & 100.0 \\
Age & Male & 139 & 29.3 & 29.4 \\
& Female & 333 & 70.3 & 100 \\
& $25-$ & 50 & 10.5 & 10.6 \\
& $26 \sim 35$ & 203 & 42.8 & 53.6 \\
Education & $36 \sim 45$ & 153 & 32.3 & 86.0 \\
& $46 \sim 55$ & 59 & 12.4 & 98.5 \\
& 56+ & 7 & 1.5 & 100.0 \\
Marriage & High school & 33 & 7.0 & 7.0 \\
Tenure (years) & College & 133 & 28.1 & 35.1 \\
& Bachelor & 276 & 58.2 & 93.3 \\
& Graduate & 31 & 6.5 & 100.0 \\
& Single & 192 & 40.5 & 40.9 \\
Total & Married & 275 & 58.0 & 99.6 \\
\hline
\end{tabular}

questionnaires to the healthcare professionals (physicians, nurses, medical technicians, and administrative staff) in a regional hospital in central Taiwan. 102 responses were deleted due to incomplete answers. 474 samples were retained for the further analyses.

The data is composed by 48 physicians (10.1\%), 206 nurses(43.5\%), 143 administrative staffs, and 76 medical technicians (16.0\%). 333 of them are female $(70.3 \%)$ compare to the male at $139(29.3 \%)$ with mostly aged 26-35(203, 42.8\%), and followed by those aged 36-45 (153, $32.3 \%), 46-55(59,12.4 \%)$ and 25 or younger $(50,10.5 \%)$, as shown in table 2.

Table 2 Sample distribution $(\mathrm{N}=474)$

\section{Results and Analyses}

We compare the values of perceived importance and the values of satisfaction for each item by dimension, and to examine the t-value of these differences to see if any aspects of the satisfaction measurement are significant. By doing this, we can reveal the leaks that exists in the employee's expectation, and that will bring important message to the management for an effective resource allocation.

\subsection{Evaluation and promotion}

All items are far below the employee's expectation, ranging from -1.05 (A1) to -1.23 (A7), 
and the item A7 (development opportunity) and A5 (effects of evaluation) are marked the biggest two, as shown in table 3. Noteworthy is that the A5 is been perceived as the most important item in this aspect. A5 may be worth to be included as some first priorities in drafting next human resource management project.

\subsection{Compensation and training system}

Again, the respondents experienced low satisfaction in the compensation system. Moreover, the gaps in this dimension are the biggest across all dimensions. This may imply that the respondent are highly unsatisfied with what they been treated in terms of compensation. Since training and school education inside and outside the organization means possible promotion and better salary in the future, training program and on-the-job school education are also included in this dimension.

Table 3 Differences in performance evaluation

\begin{tabular}{lcccc} 
Items & $\begin{array}{c}\text { Importance } \\
(\mathrm{A})\end{array}$ & $\begin{array}{c}\text { Satisfaction } \\
(\mathrm{B})\end{array}$ & Dif. (B-A) & t-test \\
\hline aluation & 4.12 & 3.07 & -1.05 & $17.878^{* * * *}$ \\
ion system & 4.18 & 2.90 & -1.28 & $20.264^{* * * *}$ \\
pportunity & 4.13 & 2.83 & -1.30 & $20.564^{* * * *}$ \\
g criteria & 4.22 & 3.05 & -1.17 & $20.008^{* * * *}$ \\
valuation & 4.26 & 3.04 & -1.22 & $20.648^{* * * *}$ \\
aluation performance & 4.13 & 3.03 & -1.10 & $19.105^{* * * *}$ \\
ft opportunity & 4.14 & 2.91 & -1.23 & $20.843^{* * * *}$ \\
f career development & 4.07 & 2.89 & -1.18 & $19.599^{* * *}$ \\
\hline
\end{tabular}

A1 Effective evaluation

A2 Fair evaluation system

A3 Promotion opportunity

A4 Clear grading criteria

A5 Effects of evaluation

A6 Reliable evaluation performance

A7 Development opportunity

A8 Assistance of career development
4.18

4.26

4.14

2.89

2.90

3.05

3.04

Negative dif. (B-A) denotes that the employee experienced lower than they expected in such item. ${ }^{* * *} p<0.001$

The least gap in this dimension is found for the relevance of job training to the job requirement at $-0.99(\mathrm{t}=18.849)$, and in the meantime the training program provided by the hospital is perceived as the least important one ironically. The major gaps are found in "performance bonus" $(-1.47, \mathrm{t}=20.014)$ and "salary-performance equity" $(-1.49, \mathrm{t}=23.855)$, of which closely related with monetary payment and performance. This indicates that these professionals generally complain their performances were undervalued. In a healthcare facility such as in the hospital of the current research, the physicians typically receive greater portion of the performance bonus, and the rest of the healthcare team share the balance. Other difference between perceived importance and experience is ranging from -1.05 and -1.46 , as shown in table 4.

Table 4 Differences in the compensation system

\begin{tabular}{lcccc}
\hline \multicolumn{1}{c}{ Items } & Importance (A) & Satisfaction(B) & Dif. (B-A) & t-test \\
\hline B1 Fair compensation system & 4.36 & 2.93 & -1.43 & $23.494^{* * * *}$ \\
B2 Professional stipend & 4.42 & 2.96 & -1.46 & $25.143^{* * * *}$ \\
B3 Performance bonus & 4.40 & 2.93 & -1.47 & $20.041^{* * * *}$ \\
B4 Salary-performance equity & 4.40 & 2.91 & -1.49 & $23.855^{* * *}$ \\
B5 Salary-position equity & 4.35 & 3.03 & -1.32 & $22.119^{* * *}$ \\
\hline
\end{tabular}


B6 Retire system

\subsection{8}

B7 Paid on-the-job education

B8 Relevance of job training
4.36

4.31

Negative dif. (B-A) denotes that the employee experienced lower than they expected in such item. ${ }^{* * *} p<0.001$

\subsection{Job content}

There are seven items in the dimension of job content, including from the nature of the job such as independence and responsibility, to the outcomes of the job such as the importance of the job to the hospital and the knowledge the employee can learn from the job. All differences again are negative but narrower than the rest dimensions, as shown in table 5, ranging from -0.65 to -0.91 . Interesting to note is that the respondents generally viewed items in this dimension are less important. As far as the job content concern, respondents are generally satisfied and accordingly pay less attention on this particular aspect. This may explain why the perceived importance is low in the items of this dimension. This dimension may need less effort among the others, because of the short distance of expectation and experience and the low levels of perceived importance.

Table 5 Gaps in the job content

\begin{tabular}{lcccc}
\hline \multicolumn{1}{c}{ Items } & Importance (A) & Satisfaction(B) & Dif. (B-A) & t-test \\
\hline C1 Independence & 4.16 & 3.51 & -0.65 & $14.384 * * *$ \\
C2 Free decision- making & 4.21 & 3.54 & -0.67 & $14.469 * * *$ \\
C3 Job enrichment & 4.09 & 3.43 & -0.66 & $14.466 * * *$ \\
C4 Job achievement & 4.22 & 3.38 & -0.84 & $17.040 * * *$ \\
C5 Values of job outcomes & 4.14 & 3.39 & -0.75 & $15.864 * * *$ \\
C6 Learning from the job & 4.21 & 3.39 & -0.82 & $17.611 * * *$ \\
C7 Recognition from the job & 4.30 & 3.39 & -0.91 & $17.845 * * *$ \\
\hline
\end{tabular}

Negative dif. (B-A) denotes that the employee experienced lower than they expected in such item. ${ }^{* * *} p<0.001$

\subsection{Work environment}

Seven items are used to measure the dimension of work environment, of which mainly addressing the issues associated the safety and security when performing works. "Overall work environment quality" and "Job safety program" are the top two issues the respondents perceived as important with average score at 4.40, as shown in table 6. 
Table 6 Gaps in the dimension of work environment

\begin{tabular}{lcccc}
\hline \multicolumn{1}{c}{ Items } & $\begin{array}{c}\text { Importance } \\
(\mathrm{A})\end{array}$ & $\begin{array}{c}\text { Satisfaction } \\
(\mathrm{B})\end{array}$ & $\begin{array}{c}\text { Dif. } \\
(\mathrm{B}-\mathrm{A})\end{array}$ & t-test \\
\hline $\begin{array}{l}\text { D1 Care of the comfort ability and safety } \\
\text { of work environment }\end{array}$ & 4.33 & 3.26 & -1.07 & $19.570^{* * * *}$ \\
$\begin{array}{l}\text { D2 Care about employee's health and } \\
\text { safety }\end{array}$ & 4.39 & 3.42 & -0.97 & $19.948^{* * *}$ \\
$\begin{array}{l}\text { D3 Hospital's ability in maintaining a } \\
\text { safety environment }\end{array}$ & 4.38 & 3.41 & -0.97 & $18.403^{* * * *}$ \\
$\begin{array}{l}\text { D4 Overall work environment quality } \\
\text { D5 Administrative support to the }\end{array}$ & 4.40 & 3.17 & -1.23 & $22.103^{* * * *}$ \\
employee & 4.34 & 3.05 & -1.29 & $21.541^{* * *}$ \\
$\begin{array}{l}\text { D6 Implement a program about the } \\
\text { employee's job safety }\end{array}$ & 4.40 & 3.24 & -1.16 & $55.588^{* * *}$ \\
$\begin{array}{l}\text { D7 Complete safety and security } \\
\text { facilities }\end{array}$ & 4.37 & 3.13 & -1.24 & $21.780^{* * *}$ \\
\hline
\end{tabular}

Negative dif. (B-A) denotes that the employee experienced lower than they expected in such item. ${ }^{* * *} p<0.001$

Noteworthy is that these two items are not the worst from the employee's experience. It seems the hospital is doing well in this environment issue. The major complain is found on the support from administrative staff $(-1.29, \mathrm{t}=21.541)$. This may imply that the administrative procedures may need a further simplification. The rest average scores are slightly lower than 4.40, and the gaps are ranging from -0.97 to -1.24 .

\subsection{Supervision}

The supervision dimension contains seven items to measure the respondents' opinions on the importance of the leaders in their jobs as well as the actual experience they have encountered. Research results indicates that timely assistance from supervisors (beyond oral instruction) when caring a patient is perceived as the most important feature in terms of the leadership. The most apparent gaps between expectation and experience is found for "fair job loading" $(-1.06, \mathrm{t}=19.638)$, as shown in table 7 .

Table 7 Differences in the dimension of supervision

\begin{tabular}{lcccc}
\hline Items & $\begin{array}{c}\text { Importance } \\
(\mathrm{A})\end{array}$ & $\begin{array}{c}\text { Satisfaction } \\
(\mathrm{B})\end{array}$ & $\begin{array}{c}\text { Dif. } \\
(\mathrm{B}-\mathrm{A})\end{array}$ & t-test \\
\hline $\begin{array}{l}\text { E1 Supervisors provide clear job } \\
\text { instruction }\end{array}$ & 4.33 & 3.43 & -0.90 & $17.987^{* * *}$ \\
E2 Providing timely and sufficient & 4.39 & 3.41 & -0.98 & $18.949^{* * *}$ \\
assistance & & & & \\
E3 Fair job loading & 4.35 & 3.29 & -1.06 & $19.638^{* * *}$ \\
E4 Timely recognition or praise & 4.29 & 3.36 & -0.93 & $17.325^{* * *}$ \\
E5 Transparent communication from the & 4.28 & 3.46 & -0.82 & $16.103^{* * *}$ \\
management & & & & \\
E6 Constant goals of the hospital & 4.30 & 3.34 & -0.96 & $18.183^{* * *}$ \\
$\begin{array}{l}\text { E7 Leader's ability in solving disputes } \\
\text { among colleagues }\end{array}$ & 4.32 & 3.35 & -0.97 & $17.618^{* * *}$ \\
\hline
\end{tabular}

Negative dif. (B-A) denotes that the employee experienced lower than they expected in such item. ${ }^{* * *} p<0.001$

It is not uncommon to realize that the respondents complain the most of this item. As a matter 
of fact, subordinates professional capability can never maintain at the same standard. Such an inequality of capability is always a challenge to a supervisor or unit leader while designing and distributing works. Gaps for other items appear to not such serious as items in other dimensions. Communication among top management, supervisors, and the staffs seems fine in terms of giving praise or forwarding the corporate policy.

\subsection{Interpersonal relationship}

The dimension of interpersonal relationship contains five items, including the quality of interpersonal relationship in the same department as well as across different departments. Quality communication is perceived as the most important issue in this dimension (mean=4.34), and received biggest gap from the respondent's experience $(-1.08, \mathrm{t}=21.61)$, as shown in table 8 . The second gap is found for benevolence from other department $(-1.04$, $\mathrm{t}=19.251)$ of $\mathrm{F} 4$, yet the respondents perceived this as the least important in this dimension $($ mean $=4.25)$. The least gap is the $F 1$, regarding a situation of maintaining a cordial relationship with cooperative units.

Respondents of this research experienced most satisfied with "free decision-making" of the dimension of work environment, and least with "promotion opportunity" of evaluation dimension. This may be interpreted as the respondents are highly active in getting promotion opportunity, and they are willing to take relevant training and education, as well as fair evaluation system to gain this opportunity. Interesting as well to note is the employee of the focal hospital is willing to take challenge, which is good for vitality of the human resource capital. In the other hand, there many aspects in the human resource management the hospital are far below the employee's experiences, such as those items with major gaps in the compensation system, and thus need certain advanced efforts.

Table 8 Gaps in the dimension of inter-personal relationship

\begin{tabular}{lcccc}
\hline \multicolumn{1}{c}{ Items } & $\begin{array}{c}\text { Importance } \\
\text { (A) }\end{array}$ & $\begin{array}{c}\text { Satisfaction } \\
(\mathrm{B})\end{array}$ & $\begin{array}{c}\text { Dif. } \\
\text { (B-A) }\end{array}$ & t-test \\
\hline $\begin{array}{l}\text { F1 Harmonious relationship with } \\
\text { cooperative departments }\end{array}$ & 4.33 & 3.44 & -0.89 & $19.530^{* * * *}$ \\
$\begin{array}{l}\text { F2 Good communication channels } \\
\text { across departments }\end{array}$ & 4.34 & 3.26 & -1.08 & $21.610^{* * * *}$ \\
$\begin{array}{l}\text { F3 Coordination and conflict } \\
\text { arbitration for teamwork }\end{array}$ & 4.29 & 3.34 & -0.95 & $19.147^{* * * *}$ \\
$\begin{array}{l}\text { F4 Benevolence from coordinating } \\
\text { departments }\end{array}$ & 4.25 & 3.21 & -1.04 & $19.251^{* * * *}$ \\
$\begin{array}{l}\text { F5 Close coordination across } \\
\text { departments for shared mission }\end{array}$ & 4.31 & 3.29 & -1.02 & $19.654^{* * * *}$ \\
\hline
\end{tabular}

Negative dif. (B-A) denotes that the employee experienced lower than they expected in such item. ${ }^{* * *} p<0.001$

Compare to perceived importance, the employees significantly experienced lower levels of satisfaction $(p<0.001)$. The biggest gap is found in the "salary-performance equity" in the dimension of compensation system $~ I n$ fact, the top five gaps throughout the entire items in question are in the compensation system. This simply confirmed that compensation would still remain the core in fostering employee's job satisfaction. The bottom five gaps are found 
mainly in the dimension of job content. This implies that the hospital provide ample room form job enlargement and job enrichment, or respondents were well-trained and are qualified healthcare professionals who are highly able to accomplish jobs independently.

\section{Conclusion and Implications}

Professional stipend, performance bonus, and salary-performance equity are perceived by the employees as most important items that contribute to their job satisfaction. Unfortunately, these receive significantly lower than the average scores in the respondents' measurements. Since respondents are very much care about these items than the others, the fact of such distances may not be offset by other items, such as work environment or job content. As a result, the overall job satisfaction can be lower than it should be. Comparing with the compensation aspect, the respondents appear to pay less attention to work environment and supervision. This may truly reflect that the employees are rather confident with their own professional expertise and their communication with their leaders. The much shorter distances in the items of less important aspects may stem from their dissatisfaction with compensation. To the least, the dissatisfaction on less important dimensions may have been affected by the negative emotion on compensation.

Several items in the dimension of job content also received greater attention in particular the job enrichment and the job achievement. Noteworthy is the respondent perceived less distance than those in the compensation dimension. The hospital has successfully motivated the employee's morale through certain practices such as job enrichment and job enlargement. To be more effective, a further improvement in the equity of performance and salary would be recommended.

\section{References}

Alamro, A. \& Rowley, J. (2011) Antecedents of brand preference for mobile telecommunications services. Journal of Product \& Brand Management, 20(6), 475 - 486.

Baker, J. (1987). The role of the environment in marketing services: The consumer perspective. In J. Czepiel, C. Congram, \& J. Shanahan (Eds.), The services challenge: Integrating for competitive advantage (pp. 79-84). Chicago: American Marketing Association.

Baker, J., Berry, L. L., \& Parasuraman, A. (1988). The marketing impact of branch facility design. Journal of Retail Banking, 10(2), 33-42.

Barbara, A. A., Jaffe, W., \& Lin, L. (1994). Use of the service attribute matrix to measure consumer satisfaction, Journal of Hospitality and Tourism Research, 17(2), 63-75. doi: 10.1177/109634809401700207

Bitner, M. (1992). Servicescapes: The impact of physical surroundings on customers and employees. Journal of Marketing, 56, 57-71.

Christen, M., Iyer, G., \& Soberman, D. (2006). Job satisfaction, job performance, and effort: A reexamination using agency theory. Journal of Marketing, 70, 137-150.

Hammasi, M., Strong, K. C., \& Taylor, S. A. (1994).Measuring service quality for strategies planning and analysis in service firms. Journal of Applied Business Research, 10(4), 24-34.

Hoppock, R. (1935). Job satisfaction. New York: Harper and Brothers, p. 47.

Lovelock, C. H., \& Wirtz, J. (2010). Service marketing ( $7^{\text {th }}$ eds.). NJ: Prentice Hall. 


\section{Macrothink}

Journal of Sociological Research

ISSN 1948-5468

2013, Vol. 4, No.2

Oliver, R. L. (1993). Cognitive, affective, and attribute bases of the satisfaction response. Journal of Consumer Research, 20(3), 418-430.

Oliver, R.L. (1980).A cognitive model of the antecedents and consequences of satisfaction decisions. Journal of Marketing Research, 17(4), 460-469.

Turley, L. W., \& Milliman, R. E. (2000). Atmospheric effect on shopping behavior: A review of the experimental evidence. Journal of Business Research, 49(2), 193-211.

Vroom, V.H. (1964). Work and motivation. New York: John Wiley and Sons, p.99. 